\title{
OPTIMIZATION OF THE INFRASTRUCTURE OF REINFORCED CONCRETE RESERVOIRS BY A PARTICLE SWARM ALGORITHM
}

\author{
Saeed KIA ${ }^{1}$, Mohammad Hassan SEBT ${ }^{2}$, Vahid SHAHHOSSEINI ${ }^{2}$
}

\begin{abstract}
Optimization techniques may be effective in finding the best modeling and shapes for reinforced concrete reservoirs $(R C R)$ to improve their durability and mechanical behavior, particularly for avoiding or reducing the bending moments in these structures. RCRs are one of the major structures applied for reserving fluids to be used in drinking water networks. Usually, these structures have fixed shapes which are designed and calculated based on input discharges, the conditions of the structure's topology, and geotechnical locations with various combinations of static and dynamic loads. In this research, the elements of reservoir walls are first typed according to the performance analyzed; then the range of the membrane based on the thickness and the minimum and maximum cross sections of the bar used are determined in each element. This is done by considering the variable constraints, which are estimated by the maximum stress capacity. In the next phase, based on the reservoir analysis and using the algorithm of the PARIS connector, the related information is combined with the code for the PSO algorithm, i.e., an algorithm for a swarming search, to determine the optimum thickness of the cross sections for the reservoir membrane's elements and the optimum cross section of the bar used. Based on very complex mathematical linear models for the correct embedding and angles related to a
\end{abstract}

\section{Address}

1 Amirkabir University of Technology, Tehran Polytechnic, Iran 2 Department of Civil \& Environmental Engineering, Amirkabir University of Technology, Tehran Polytechnic, Iran

* Corresponding author: skia@aut.ac.ir

\section{Key words}

- Concrete Reservoirs,

- infrastructure,

- health monitoring,

- optimization,

- Particle Swarm Algorithm.

chain of peripheral strengthening membranes, which optimize the vibration of the structure, a mutual relation is selected between the modeling software and the code for a particle swarm optimization algorithm. Finally, the comparative weight of the concrete reservoir optimized by the peripheral strengthening membrane is analyzed using common methods. This analysis shows a 19\% decrease in the bar's weight, a 20\% decrease in the concrete's weight, and a minimum 13\% saving in construction costs according to the items of a checklist for a concrete reservoir at $10,000 \mathrm{~m}^{3}$.

\section{INTRODUCTION}

Nowadays, the use of reinforced concrete structures in order to save water or other aqueous liquids has greatly expanded. In this regard, an appropriate design and exact implementation is of particular importance when building structures with a high degree of quality and economic efficiency as defined in Lloyd and Doyle (1978). Any structure that is designed to hold liquids should possess stability, resistance, and sufficient strength against deformation and cracking.
The design and simulation should be performed in such a manner that the liquid cannot penetrate or infiltrate the concrete structures, which is discussed by Mohaghegh (2011). In typical structures, the main aspect of the design is the structural stability and resistance against loads. But when designing liquid holding tanks, the structure should be resistant to penetration and leakage in addition to possessing structural stability and strength. Thus, a concrete cover for a bar should be considered in these structures. So, based on recent studies such as Chen and Kianoush (2009), we can note that designing liquid holding 
structures is more complicated and sensitive than designing general structures because of the importance of the structure's coefficients, the effect of seismic loads, and the priority of the structure based on each country's civil infrastructure categories.

In the past, designing concrete structures was done based on an elastic theory that the control of the maximum tension under loads was due to their foundations. Designing liquid holding structures was performed according to the amounts authorized based on elastic relations and with limited material stresses. For this reason, when designing structures, thick sections of concrete with a large amount of steel were used. At that time, analyzing the possibility of thermal cracking and cracking due to the concrete cast was not performed based on acceptable bases. Also, only a nominal amount of steel is mentioned in the regulations. In recent years, a limit state with a more rational basis has been introduced to determine the safety factors. In this method, in designing a structure, load coefficients have been used with the ultimate strength of the materials. In order to calculate the flexural crack width and compare it with the maximum allowable amount, analytical methods have been developed. In addition, methods of calculating the effects of thermal strains and where these strains are caused by the loss of drying concrete have been considered. With the mentioned advances the limit state method has been used to design liquid holding structures. With the design method of limit states, it is possible to identify and evaluate possible failure modes of structures for the designers as the premature rupture of structures can be avoided during times when these problems change. Ziari and Kianoush (2009) investigated mathematical formulations for flexural cracking and leakage in RCR structures.

In this research, regarding the structure of a concrete reservoir's uniformity and based on the amount of input and output water divided into $1000,5000,10000,20000$, and $30000 \mathrm{~m}^{3}$, a reservoir was first selected with an input discharge amount of $10,000 \mathrm{~m}^{3}$ according to the maximum design conditions in Iran. According to the analysis conducted and based on the assumptions discussed, a range of thickness of the shell elements and the bar usage has been determined according to the maximum tension in the structure. Then, by using the Parameter Identification System (PARIS) algorithm by Sanayei et al (2007), which used measurements for stiffness and mass parameter estimations of the structural modal elements, the computational software algorithm is connected by the finite element method (FEM) with the reinforced reservoir structural model. The written code of the Matlab software for optimizing the particle significance of a modeling error, which was provided by Sanayei et al (2001), was selected to achieve the optimal levels in this bilateral relationship. Finally, for using the confirmatory sheath surrounding it, each of the optimized parameters are evaluated again regarding the relevant provisions in the analysis process so that their orientation is clear.

\section{OPTIMIZATION ISSUES}

Lianghsu (1994) categorized optimization issues into two groups: limited and unlimited issues. In optimizing structures because numerous bonds exist to confine the tensions, transfigurations and consumable materials, we mostly deal with bound issues. The issue of optimizing concrete holding reservoirs of fluids is a limited issue too. There are different ways to convert a limited issue into one without bounds; the most common one is the application of a penalty function, which has been used in the present study. Now that we can express the overall optimization issues, an optimization issue can be considered as:

$\min i m i z e: F(\{X\})$,

$$
\text { subject }:\left\{\begin{array}{l}
g_{i}(\{X\}) \leq 0 \\
h_{j}(\{X\})=0
\end{array}\right\}\left[\begin{array}{c}
i=1,2, \ldots, m \\
j=1,2, \ldots, n
\end{array}\right],
$$

$$
\left(X_{L}\right) \leq(X) \leq\left(X_{U}\right) .
$$

The vector in relation (1) indicates the design variables, and the symbol indicates the function of the optimization issue, which is considered on a scale for various designs and the top layout selection. It is clear that the optimization of the objective function should not adversely affect the structure's behavior and its efficiency. Then it is necessary to meet the optimal objective function inequalities of relation (2), which is called the constraint issue. The parameters involve the circumstances which warrant a range of changes in the amplitude, the ability to withstand structural loads, and other applicable standards. In this way the minimum and maximum limits of the amount of the bar used, the changes in the vessel wall's thickness, the highest amount of tension, and the largest shift can be mentioned. Finally, relation (3) indicates the limitations which affect the design variables because of the structural considerations of the non-behavioral implementation coefficient defined by Perez and Behdinan (2007).

\section{DESIGN OF REINFORCED CONCRETE RESERVOIRS}

\subsection{Basic details}

In the construction of a water supply, water reservoirs are used in order to coordinate production and water use and to regulate the pressure in a water supply network. Dewatering constructions and water refinements are designed based on the utilization of a maximum discharge on a daily to weekly basis. Considering the economic aspects of the design and exploitation, the construction should be performed in a manner that could provide the required water in an identical process during the day, as defined by Chen and Kianoush (2009). Based on Chau and Lee (1991), it is clear that water consumption in a city could not be a function of this identical process. Water consumption at different hours, depending on the conditions, may vary up to several times daily. To reduce or eliminate the impact of these fluctuations and create a degree of coordination between the consumption and production, it is justifiable to build coordinator and regulator reservoirs. According to the research from Thevendran and Thambiratnam (1987), which tried to formulate the optimal shapes of cylindrical concrete water tanks, these concrete reservoirs can be built anywhere in the water supply construction and can protect against drastic changes in hourly water consumption. If the conditions require it, an appropriate location for this repository is in the water distribution or behind it. In this position, the transmission lines and dewatering construction and refinements are protected from changes in consumption, and the cost of the design's utilization are appropriate from an economic perspective.

In this study, a concrete storage tank with a $10,000 \mathrm{~m}^{3}$ water network was selected regarding the assimilation of the structural elements in buried rectangular reinforced concrete reservoirs. At this stage, the thickness of the walls, foundation and roof were selected to achieve a marginal ambit of the bonds. In the next stage with the finite element method and with the help of computational analysis, the amplitude of the sidewalls of the tank shell was selected regarding the lateral and intermediate positions, by considering the inside and outside conditions and assuming the effect of the water power loading inside the tank on a double reciprocal basis in the case of a full amount of water. Among the proposed elements, the range of el- 
ements that have a maximum tension were chosen at first to calculate the optimum thickness of the shell wall and the amount of the optimal bars used; then in the next stage, these investigated parameters were evaluated based on the confirmatory cover.

\subsection{Assumptions of the calculations}

In the present study, some assumptions have been chosen based on the modeling accomplished regarding the structural types of reinforced concrete reservoirs. The reservoir structure selected is on a scale of $10,000 \mathrm{~m}^{3}$. The maximum water balance in the reservoir is equal to $+4.70 \mathrm{~m}$ towards the bed's balance. The dimensions of the reservoir structure's balances in the bed are equal to $41.60 \mathrm{~m}$ in width, $61.60 \mathrm{~m}$ in length, and a height of $+5.35 \mathrm{~m}$ equal to $40.60 \mathrm{~m}$ in width and $60.60 \mathrm{~m}$ in length. In order to increase confidence and reduce the tension levels at the foot of the walls, a $30 \mathrm{~cm}$ wide heel is intended for the bed. The reinforced concrete reservoir's structure includes the surrounding concrete walls with a $5.10 \mathrm{~m}$ height and a $40 \mathrm{~cm}$ soil embankment in the RCR roof. This structure is considered to be half buried in the ground, and there is no possibility of the movement of vehicles on the roof of the tank regarding the protection of cargo.

The concrete materials used in the tank are considered with regard to the required resistance and also the desired structural performance with a minimum 28 days of compressive strength of its cubic sample equal to $35 \mathrm{MPa}$ and a minimum amount of cement used, which is equal to $40 \mathrm{MPa}$. In preparing the concrete, the maximum water-cement ratio is presumed to be 0.45 , and the commixture design would be available to the administrative operation in the construction of structures regarding the existing conditions. The type of bar used in the different parts of the concrete structure (the foundations, walls, ceiling and columns) are class AIII rebar with a characteristic yield strength of $f_{y k} 400$ to $420 \mathrm{~N} / \mathrm{mm}^{2}$ for the persistence required with an appropriate elastic reaction between the steel and concrete materials and their simultaneous performance.

The soil on the site is considered to be type II. The soil bearing capacity and specific weight of the soil at the site is assumed to be equal to $\mathrm{q}_{\mathrm{a}}=1 \mathrm{~kg} / \mathrm{cm}^{2}$ and $\gamma_{\text {soil }}=2000 \mathrm{~kg} / \mathrm{m}^{3}$ respectively. The groundwater level on the construction site is considered to be below the bed balance; therefore, the static and dynamic lateral loading of the water resulting from an earthquake around the structural walls is not defined.

The location of the operation was selected to be in a city with a high ratio of earthquake risks so that the values of an earthquake's power and the dynamic loads of water and soil on the structure can be calculated. To calculate the coefficient of an earthquake, the structural site, a high risk earthquake rate, and the maximum acceleration of an earthquake equal to $0.3 \mathrm{~g}$ are considered. In addition, it is considered that the structure is related to a water supply installation; and the structure with a high degree of importance and an importance coefficient (IC), which is equal to 1.4 , is considered. Also, a behavior coefficient equal to 3 is considered in order to apply the lateral seismic loads of an earthquake on the reinforced concrete reservoir's structure and the dynamic pressures of the water and ground. This is based on the plasticity and depreciation feature of the low energy of these structures. Under the terms of the regulations, in order to apply the terms of the elements' cracking, the effects of the reduction in resistance, and the effects of the reduction in each of their cross sections, an effective cracking coefficient in the members' moment of inertia is considered to be 0.70 around axes $\mathrm{y}$ and $\mathrm{z}$ for the columns, which means $30 \%$ less than the total members' moment of inertia capacity. Also, the effects of the reduced stiffness due to fractions are assumed to be 0.70 in the shear concrete walls and 0.25 in the ceiling, and the rigidity of the rigid end-users in the joint members at the connections is also assumed to be equal to 0.50 .

\subsection{Elements of the structure}

The thick shell elements for the surrounding walls, foundation and roof are defined based on previous experience in modeling regarding the dimensions of each element and its loading conditions, so that by reducing tension in the walls and movements towards the reservoir roof's thickness, the values gradually declined. Also, in the foundation that these walls are connected to, a greater amount of thickness is defined in order to provide the appropriate charisma and freightage at the foot of the walls, where these amounts are reduced by moving towards the reservoir's center regarding the decrease in the tension levels. In defining these elements, the direction of the local axes pursuant to the original design assumptions and structural loading circumstances is defined.

The dimensions of the sections of the column frames, which are based on the values of the loads applied, have been studied, subject to the size of any craters, the structure's height and the loading conditions, and also previous experience. Regarding the loading conditions, the ease of the framing, and bar bending, and the thickness of the roof were initially intended in the models. In defining these elements, the direction of the local axes is defined according to the design of the original assumptions and the cracking column sections. Based on the regulations and the reductive effect of the rigidity at the junctions, the models are also defined. The primary dimensions of the columns are considered due to previous experience from modeling, and with regard to the mouthpiece's length, the height of the structure and the values of the loads applied are equal to $0.4 * 0.4 \mathrm{~m}$. In addition, the number of bars are primarily assumed to be equal to eight in each column. The rebar consumption of each surface side of the elements has been estimated to be between 0.4 and 4 percent, and based on ACI 318-14, the cover of each element based on corrosion is estimated to be $0.05 \mathrm{~m}$.

\subsection{Loading parameters}

In order to define different types of loads, the terms of the regulations are applied due to the fact that the structure is half-buried in the soil and is under static and dynamic water pressure. For the lateral forces of an earthquake on the reservoir's structure, the seismic coefficient amount of $\mathrm{C}$ equal to 0.35 is used, and after the initial analysis and calculated intermittence time, an assumption of the authenticity of the reflection coefficient is selected equal to an estimation of 2.5. A modal analysis of the performance and the correct definition of the reservoir's alternation time in the model and the earthquake was undertaken. The structural tank loading by using a seismic coefficient requires defining an effective mass for the structure during an earthquake, so regarding the concepts of an earthquake analysis, this mass is defined as the sum of a dead load with a 0.2 live load in the model.

In brief, the loads on the structure during the calculations are a total of the dead load, which is equal to $720 \mathrm{~kg} / \mathrm{m}^{2}$, and a $150 \mathrm{~kg} / \mathrm{m}^{2}$ snow load according to the relevant criteria. The weight of the shell elements and frames available in the models are recorded in the increasingly dead load by applying coefficient 1 in the load definition. Regarding the fact that the structure has been half-buried in the soil and the amount of the contact between the structure and the soil, the effects of the lateral pressure of the soil on the elements of the walls must be applied. So the coefficient of the lateral pressure of the soil in a one-meter width of the wall is calculated as equal to $2570 \mathrm{~kg} / \mathrm{m}^{2}$.

Changes in the soil pressure during an earthquake for the application of lateral soil pressure in the dynamic mode can be found through the relation developed by Whitman and Sid [19], which is based on the design criteria and the calculation of the ground water. In addition, the resulting dynamic pressure on the shell elements of the bur- 
ied-in-soil sidewalls can be applied. So this variable varies at a height of $3 \mathrm{~m}$ from $1570 \mathrm{~kg} / \mathrm{m}^{2}$ to the reservoir bed level. The lateral pressure and vertical fluids are calculated by the theory of fluid mechanics in accordance with the relation, which is the lateral pressure or vertical fluid that is the specific gravity of the liquid, and $y$ is the desired depth of the balance. Regarding this structure's use and the existence of 4.7 $\mathrm{m}$ water in the reservoir, the side effects of the water pressure must be entered into the elements of the shell surrounding the concrete walls; also, the vertical pressure resulting from the weight of the water on the reservoir bed has been entered. The specific weight of the water is considered equal to $1000 \mathrm{~kg} / \mathrm{m}^{2}$, and the amount will be estimated as $4700 \mathrm{~kg} / \mathrm{m}^{2}$.

In loading the repository, the structure's wall is assumed to be a hard structure, so according to Hasner's theory [19], the fluid dynamic model is the same with two degrees of freedom with the water's viscosity, which is in a reservoir with a hard wall. A degree of freedom is related to a mass which contains the weight of a liquid part that vibrates along the reservoir and is called a hard mass $\left(\mathrm{w}_{1}\right)$, and the level of freedom contains the weight of a liquid part that vibrates independently in alternative times much greater than the alternative times of the hard part. The structure is called a sloshing mass $\left(\mathrm{w}_{2}\right)$. Regarding the changes in water pressure during an earthquake, in order to apply this lateral pressure in the dynamic mode, the existing relations in the criteria, the design scales, and the calculation of the groundwater can be used; and the resulting dynamic pressure can be applied to the elements of the side wall shell. This raster measure for two $\mathrm{q}_{1}$ measures is equal to $1550 \mathrm{~kg} / \mathrm{m}^{2}$ in the ceiling and $3970 \mathrm{~kg} /$ $\mathrm{m}^{2}$ in the bed; in addition, the raster for the two $\mathrm{q}_{2}$ measures is equal to $1.71 \mathrm{ton} / \mathrm{m}^{2}$ in the ceiling and $4130 \mathrm{~kg} / \mathrm{m}^{2}$ in the bed. In order to apply the forces resulting from a change in temperature on the shell elements, a change in temperature is applied equal to $293.15^{\circ} \mathrm{K}$ on these members regarding this structure in the earth and the bulwark on the roof. According to the modeling and analysis of the RCR with software, 20 load combinations for this structure were selected based on the codes and durability design of the structure. The load combinations were achieved from the dead load (DL), the soil load (SOAIL), the soil dynamic load in the $\mathrm{x}$ and $\mathrm{y}$ directions (ESOAILX/ESOAILY), the snow load (SNOW), the water load (WAT), the water load in the $\mathrm{x}$ and $\mathrm{y}$ directions (EWX/EWY), the earthquake loads in the $\mathrm{x}$ and y directions (EQx/EQy), and the temperature load (T), which relate to each other, and make 20 load combinations (Table 1).

\subsection{Modeling and software analysis}

Both as a result of the work of Rao and Hinton (1993) on the analysis and optimization base for shell structures and the use of shell elements and the need for networking and analyzing different parts of this structure for reservoir modeling, the SAP2000 finite element software with a linear analysis of the shell elements connected to the frame elements has been used. The reservoir structure is divided into six parts regarding the expansion fissures. The three models were made and checked in the abovementioned program to design the different parts of this structure. For these wall members, the thickness of the shell element regarding the length and height of the wall and its loading conditions at the junction to the foundation moving upward is reduced up to $0.08 \mathrm{~m}$ and is assumed to be at least $0.35 \mathrm{~m}$ at the junction to the ceiling. The thickness of the shear walls is assumed to be at least $0.35 \mathrm{~m}$; the foundation's thickness is assumed to be up to $0.80 \mathrm{~m}$ based on previous experience, the anchor and the transferred section from the walls. This amount has gradually been reduced by moving toward the center of the tank; it is assumed to be at least $0.40 \mathrm{~m}$ after seven meters. In addition, the thickness of the ceiling and excess soil load is intended to be at least $0.25 \mathrm{~m}$ based on experience, the anchor and the transferred cutting from the walls. After the finalization of the geometry and loading, each of the above models is analyzed by linear statics; the shell elements, and the frame elements are designed manually and by the program respectively according to the outcome.

\subsection{Results of the analysis}

After performing the analysis, the results of the linear static analysis of all the states of the loading models were applied to the manual design of the concrete structure based on the forces and anchor values resulting from the analysis of the models. To design the concrete reservoir structure formed by the shell elements, the results of the structural analysis for all the types of loads on it were studied in the shape of the determined load compounds, and the bending anchor responses and tensile forces on the wall shell, the foundation, and ceiling. The required bars for the members are calculated with additional amounts at the points of the concentrated tension by the tension anchor amounts and the design of the thickness of the structural members to resist incoming shear forces in addition to optimizing the amount of bars required to resist the anchor and extension. To control the under-foundation tensions to prevent creating an extension in the soil and also prevent increasing under-foundation tensions more than the soil's permissible tension, the amount of the foundation's vertical shift under the compounds of the foundation loading is controlled. Thus, an upheaval is not created in the foundation according to the outcomes from the modeling analysis; and the under-foundation soil is not pulled.

\subsection{Verification of the software analysis}

In order to verify the analysis of the software, a rectangular metal shell was selected and checked one time by the modeling software as a thin shell element and another time as a thick shell element. A rect-

Tab. 1 Load combinations for the RCR structural analysis.

\begin{tabular}{|ccc|}
\hline No. & Combo. Name & Load Combinations \\
\hline 1 & Comb1 & 1.4 DL+ 1.7 WAT + 1.7 SNOW \\
2 & Comb2 & 1.4 DL+ 1.7 SOAIL + 1.7 SNOW \\
3 & Comb3 & $\mathbf{0 . 7 5}($ Comb1 + 1.87 EWX + 1.87 EQx) \\
4 & Comb4 & $\mathbf{0 . 7 5}($ Comb1 + 1.87 EWY + 1.87 EQy) \\
5 & Comb5 & $\mathbf{0 . 7 5}($ Comb2 + 1.87 ESOAILX+ 1.87 EQx) \\
6 & Comb6 & $\mathbf{0 . 7 5}($ Comb2 + 1.87 ESOAILY - 1.87 EQy) \\
7 & Crackstc1 & 1DL+1WAT+1SNOW \\
8 & Crackstc2 & 1DL+1SOAIL+1SNOW \\
9 & Crackdyn1 & $\mathbf{0 . 7 5}($ Crackstc1 + EWX + EQx) \\
10 & Crackdyn2 & $\mathbf{0 . 7 5}($ Crackstc1 + EWY + EQy) \\
11 & Crackdyn3 & $\mathbf{0 . 7 5}($ Crackstc2 + ESOAILX + EQx) \\
12 & Crackdyn4 & $\mathbf{0 . 7 5}($ Crackstc2 + ESOAILY - EQy) \\
13 & TEMP1,2 & 0.75 (Comb1 + 1.4 T) \\
14 & TEMP3,4 & 0.75 (Comb2 + 1.4 T) \\
15 & FOUND1 & 1.0 DL+ 1.0 WAT + 1.0 SNOW \\
16 & FOUND2 & $\mathbf{1 . 0 ~ D L + ~ 1 . 0 ~ S O A I L ~ + ~ 1 . 0 ~ S N O W ~}$ \\
17 & FOUND3 & $\mathbf{0 . 7 5 ( F O U N D 1 ~ + ~ 1 . 0 ~ E W X ~ + ~ 1 . 0 ~ E Q x ) ~}$ \\
18 & FOUND4 & $\mathbf{0 . 7 5 ( F O U N D 1 ~ + ~ 1 . 0 ~ E W Y ~ + ~ 1 . 0 ~ E Q y ) ~}$ \\
19 & FOUND5 & $\mathbf{0 . 7 5 ( F O U N D 2 ~ + ~ 1 . 0 ~ E S O A I L X ~ + ~ 1 . 0 ~ E Q x ) ~}$ \\
20 & FOUND6 & $\mathbf{0 . 7 5 ( F O U N D 2 ~ + ~ 1 . 0 ~ E S O A I L Y ~ - ~ 1 . 0 ~ E Q y ) ~}$ \\
\hline & &
\end{tabular}




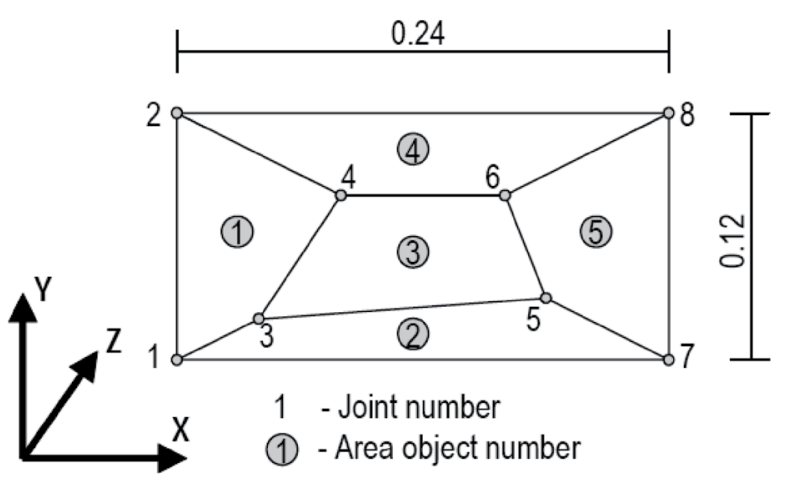

Fig. 1 Geometry of the shell for verification.

angular plate with irregularly shaped elements was subjected to the prescribed displacements at the edges that theoretically impose a constant stress field over the model. The geometry, properties and loading are as described in MacNeal and Harder (1985). The membrane and plate bending stress components resulting from the prescribed displacements were compared with the manually calculated results. Joints 1, 2, 7 and 8 were restrained for translation in the $\mathrm{X}, \mathrm{Y}$ and $\mathrm{Z}$ directions and for rotation about the $\mathrm{X}$ and $\mathrm{Y}$ axes. No joint restraint was specified about the $Z$ axis. The prescribed displacements were applied to the restrained degrees of freedom of those joints. The shell section was modeled using full shell behavior, i.e., both the membrane and plate bending behavior. Separate models were used to test the thin-plate and thick-plate options. Because the model is flat, that is, on one plane, there is no coupling between the membrane and the plate bending behavior developed by Donald and Abel (1989).

Peng (1998) developed a generalized function solution for the plate and shell elements. The primary modeling as shown in Table 2 is based on an eight-node element with 12 members and a thickness of 0.001 meters. Its supporters have nodes along the $\mathrm{x}$ and $\mathrm{y}$ diagram; they have $\mathrm{T}_{\mathrm{x}}$ and $\mathrm{T}_{\mathrm{y}}$ twists of the page along the $\mathrm{z}$ direction in nodes 3 to 6; and they are bending along the $\mathrm{M}_{\mathrm{x}}$ and $\mathrm{M}_{\mathrm{y}}$ direction in nodes 3 to 6 . The results from the software and manual calculations are shown in (Table 3).

\section{PARTICLE SWARM OF THE OPTIMIZATION ALGORITHM}

Hinton and Rao (1993) developed structural shape optimizations for shell element structures; their work was developed on two node finite strips. Based on this research, we chose Particle Swarm Optimization for the RCR structure's optimization. The PSO algorithm is an optimized technique based on the possibility rules presented by Russell A. Heart, a computer scientist, and James Kennedy, a social psychologist, in 1995. This algorithm uses the social behavior of birds during their search for food to direct a group of the birds to a promising area in the search space. The Particle Swarm Algorithm is inherently a continual optimization algorithm, and a binary version of this algorithm is used to optimize the discreet problems provided by Perez and Behdinan (2007). As mentioned, this algorithm patterns the collective behavior of birds in searching for food in a manner that a set consisting of the particle is formed so that each particle represents a bird in the search space. By adjusting the particle positions, this algorithm directs the set to the optimum solution regarding their competence.

The algorithm and flow chart which are used in this optimization is shown in Fig. 2, which relates the structural analysis to the PSO algorithm by the PARIS link. The PSO algorithm uses populations such as the hereditary algorithm, which seeks the best point of the problem space. Therefore, for each particle, the velocity scale and its direction with the other ones will be different. At the time of the relocation, the velocity obtained multiplies the inertia; it then adds to the present space of the particle.

Tab. 2 Tension and anchor calculations.

\begin{tabular}{|c|c|c|c|c|}
\hline Load case & Stress Component & Software & Independent & Percent Difference \\
\hline \multirow{3}{*}{ Membrane } & $\sigma_{x x}$ & 1333 & 1333 & $0 \%$ \\
& $\sigma_{y y}$ & 1333 & 1333 & $0 \%$ \\
& $\sigma_{x y}$ & 400 & 400 & $0 \%$ \\
Bend & $M_{x x}$ & $1.11 \mathrm{E}-07$ & $1.11 \mathrm{E}-07$ & $0 \%$ \\
& $M_{y y}$ & $1.11 \mathrm{E}-07$ & $1.11 \mathrm{E}-07$ & $0 \%$ \\
& $M_{x y}$ & $3.33 \mathrm{E}-07$ & $3.33 \mathrm{E}-07$ & $0 \%$ \\
\hline
\end{tabular}

Tab. 3 Coordinates of nodes.

\begin{tabular}{|c|c|c|c|}
\hline Joint & $X(\mathbf{m})$ & $Y(\mathbf{m})$ & $Z(\mathbf{m})$ \\
\hline $\mathbf{2}$ & 0.00 & 0 & 0.00 \\
$\mathbf{3}$ & 0.00 & 0.12 & 0.00 \\
$\mathbf{4}$ & 0.04 & 0.02 & 0.00 \\
$\mathbf{5}$ & 0.08 & 0.08 & 0.00 \\
$\mathbf{6}$ & 0.18 & 0.03 & 0.00 \\
$\mathbf{7}$ & 0.16 & 0.08 & 0.00 \\
$\mathbf{8}$ & 0.24 & 0.00 & 0.00 \\
\end{tabular}




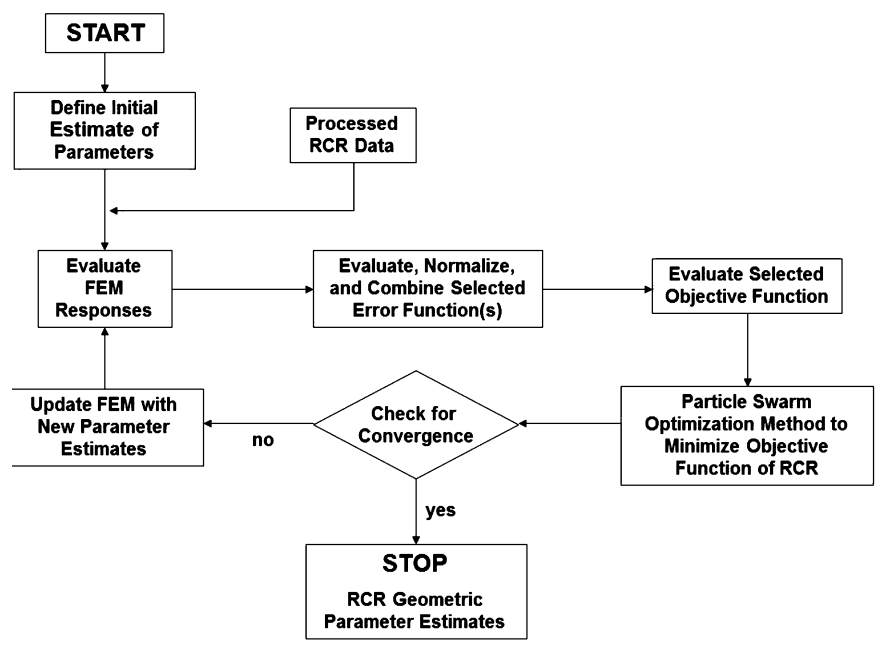

Fig. 2 PSO and PARIS algorithm flow chart.

Based on Fig. 2, PARIS is a Parameter Identification System which uses static or modal measurements for estimating the stiffness and mass parameters of the elements of the RCR structure. This algorithm is capable of handling two and three-dimensional parameter estimations of RCR, which is written in the Matlab programming language. PARIS files are compiled in the Matlab compiling language p-code for ease of transport on various platforms without any Matlab libraries, and the data files are kept in Matlab so that other data files related to the PSO algorithm can be created or modified.

In equation (4), $\varphi$ is the inertia weight coefficient with a suitable selection of inertia weights, which provides a balance between the global and local explorations. It thus requires fewer iterations on average to find a sufficiently optimal solution for a problem and, as originally developed, often decreases linearly from about 0.9 to 0.4 during a run. In general, the inertia weight is set according to the following equation based on Seok Lee and Geem's calculations (2004).

$$
\begin{gathered}
\vec{v}_{i}(t)=\varphi \vec{v}_{i}(t-1)+r_{1} c_{1}\left(\vec{x}_{p b e s t}-\vec{x}_{i}(t-1)\right)+r_{2} c_{2}\left(\vec{x}_{G b e s t}-\vec{x}_{i}(t-1)\right), \\
\vec{x}_{i}(t)=\vec{x}_{i}(t-1)+\vec{v}_{i}(t) .
\end{gathered}
$$

The coefficients of $c_{1} \& c_{2}$ are individual, and the social learning factors, the values of which shape static values ranging from 1.5 up to 2.5. $r_{1} \& r_{2}$, are selected randomly (a range of zero to 1 ) to guarantee the system's stability. In equation (5), $t$ is the iteration counter, and $\vec{x}_{i}(t) \& \vec{v}_{i}(t)$ are the velocity and position vectors respectively. Thus $\vec{x}_{p b e s t i}$ shows the best position that the space vector has had in the particle history, and $\vec{x}_{G b e s t i}$ is the best position among all the particles which was closer to the answer than the rest discussed by Sundar and Singh (2012).

$$
\varphi=\varphi_{\max }-\frac{\varphi_{\text {max }}-\varphi_{\min }}{\text { iter }_{\text {max }}} \times \text { iter }
$$

Based on the inertia weight, the coefficient calculated in equation (6), iter ${ }_{\max }$, is the maximum number of iterations (generations), and iter is the current number of iterations.

\section{THE PSO ALGORITHM APPLIED}

Optimization in a structure means access to the structural elements with a minimum weight and the best performance against static and dynamic loads with the lowest amount of vulnerability and the maximum amount of safety. At first, a range for the thickness of the structural elements in the reinforced concrete reservoir, which is based on previous experience and regarding the dimensions of the tank and its height of $5.1 \mathrm{~m}$, is selected in the model. The elements of the reinforced concrete reservoir shell with diminutions of $0.1 \mathrm{~m}$ were networked and considered according to the analysis performed in a range of the tank shell's thickness from 0.35 to $0.80 \mathrm{~m}$, the foundation from 0.35 to $0.80 \mathrm{~m}$, and the variable ceiling from 0.25 to 0.35 $\mathrm{m}$. The tank, as shown in Fig. 3, has four peripheral directions, a wall corner of which in the positive directions of $\mathrm{x}, \mathrm{y}$ and $\mathrm{z}$ is selected for the calculations, regarding the maximum tension ratio in each of the selected elements; and each of the five elements selected are as wide as the peripheral tapes along the tank's environmental shell based on the categories of the shell walls of the type of tank.
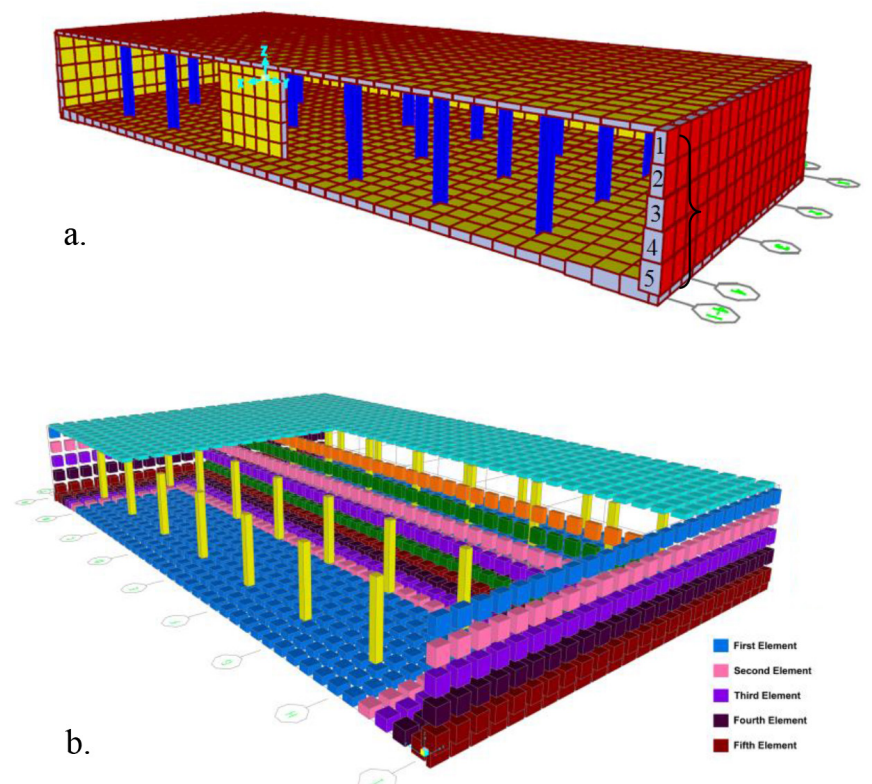

Fig. 3 (a) is the modeling and (b) is the locating of the optimized elements in the $R C R$.

First, a range of element details was created between the modeling software and the particle swarm optimization algorithm code based on the PARIS (Parameter Identification System) relations regarding the ambit of the problem space to minimize the amount of the structure's weight and control the stability under the static and dynamic loads, to minimize the selected range's thickness according to each repetition, and to optimize the bar measure per length unit used to calculate the type of bar used. After achieving the optimized elements, two peripheral sheaths were used in the shell element numbers 2 and 4 (Fig.3). The effect of this issue on the structure's behavior was evaluated in the modeling and optimizing phase. Accordingly, this reciprocal relation between the analysis and algorithm code has been done in three sections of the structure's weight reduction, achieving the minimum thickness of the tank wall's side under the loading performed and the amount of bar used to optimize the length per unit.

\subsection{The Objective Function of the PSO Algorithm}

The objective function developed by this researcher was used to minimize the weight of the structure. The $f_{d_{i}}^{W}$ as the (7) relation is a function of minimizing the tank's weight based on changing the thickness of the $i^{\text {th }}$ element; $F_{y}$ is the characteristic strength of the steel; $f^{\prime}{ }_{c}$ is the characteristic compressive strength of the concrete; $M_{u_{i}}$ is the 
ultimate flexural resistance of the anchor of the $i^{\text {th }}$ element; $\Phi$ and $\lambda$ are partial safety factors; $\gamma$ is the specific gravity of the materials; $b_{w}$ is the (structure) width; $d_{i}$ is the thickness of the $i^{\text {th }}$ element; $V_{u_{i}}$ is the ultimate shear strength of the $i^{\text {th }}$ element; $h_{i}$ is the total thickness of the $i^{\text {th }}$ element; $\alpha$ and $\beta$ are the design coefficients; $l$ is the tank length; and $b$ is the tank width. A range of the bending anchor's rate and the final cutting power is obtained to minimize the parameters involved in the tank optimization according to the analysis performed. In each of the elements, the respective function has been minimized with regard to the design criteria to the amount of the optimum thickness of the tank shell, and the bars used are calculated based on the design criteria.

$$
f_{d_{i}}^{W}=\sum_{i=1}^{5}\left(\frac{\left(1-\sqrt{1-\frac{2 \frac{F_{y}}{.85 f_{c}^{\prime}{ }_{c}} \frac{M_{u_{i}}}{\phi F_{w} d_{i}^{2}}}{F_{y}}}\right)}{\frac{F_{y}}{.85 f_{c}^{\prime}}} \alpha b d_{i} \gamma_{1}(l+b)\right)+\sum_{i=1}^{5}\left(\frac{\beta \gamma_{2} h_{i} V_{u_{i}}(l+b)}{.17 \lambda d_{i} \sqrt{f_{c}^{\prime}}}\right)(7)
$$

Regarding the existence of different variables in accordance with relation (7) and the assumptions considered to solve the problem, $M_{u_{i}}, V_{u_{i}}, d_{i}$ of the $i^{\text {th }}$ element according to Fig. 3 are considered as the scope and constraints of the problem to minimize the structure's weight. Regarding the problem solving by the particle swarm algorithm, part of the parameters used in the MATLAB software considered as the number of variables is equal to 2 ; the optimal range of the convergence number of the repetitions is equal to 80 ; the coefficient amount of the absorption of the convergence between the members is equal to 1.5 ; the primary range to select the members is 0.1 to 25 ; and the rate of convergence in the community is equal to 2 .

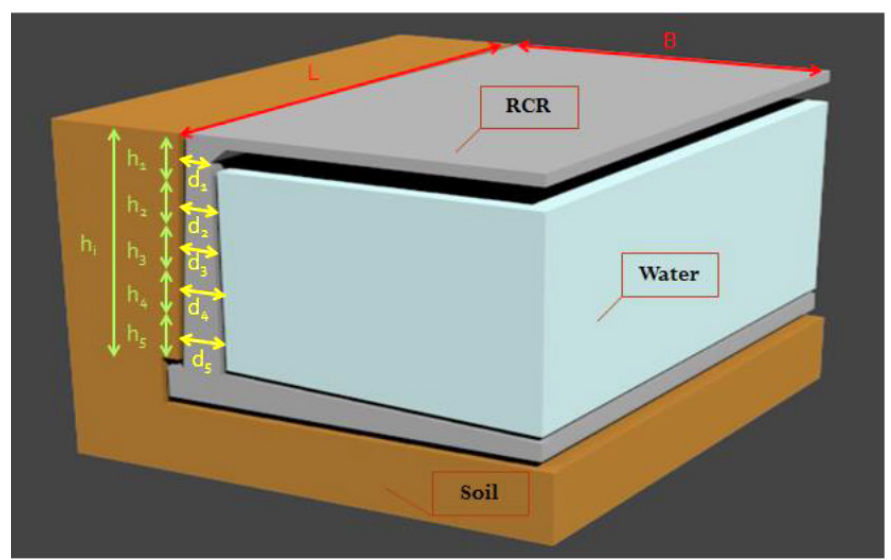

\subsection{Optimal sections selected}

After solving the functions based on the terms discussed, the optimal thickness of the reinforced concrete reservoir shell can be considered by the particle swarm algorithm methods according to Fig. 5 and is based on a comparison of the thickness of the concrete shell wall's side for the situations as seen in the tables. As shown in Fig. 4, two types of optimization are demonstrated. Based on Fig. 4, the left shows how prismatic stiffeners are placed in shear walls after the optimization of the RCR thickness based on the right figure.

Based on the PSO algorithm and computational model, this reservoir is optimized in three types which are: a) the optimized mode-design based on the theoretical numbers, b) the optimized mode design based on the executive numbers, c) the optimized mode-design by a peripheral confirmatory sheath. In Fig. 6, the amount of the bar used is studied. This section achieves the best range, which contains four phases as follows: the common mode design with the maximum bar used, the optimization of the amount of bar used based on the theoretical results, the optimization of the bar used based on the numbers with an executive possibility, and the optimization of this characteristic by the use of the confirmatory sheath. In calculating the structure by an executive method, the accuracy is based on the theoretical solution, but the respective numbers are chosen according to their executable possibilities and minimizing waste of the materials.

\subsection{Optimal weight and consumption of materials}

The performance of the particle swarm algorithm to optimize the reinforced concrete reservoirs equal to $10,000 \mathrm{~m}^{3}$ are shown in Table

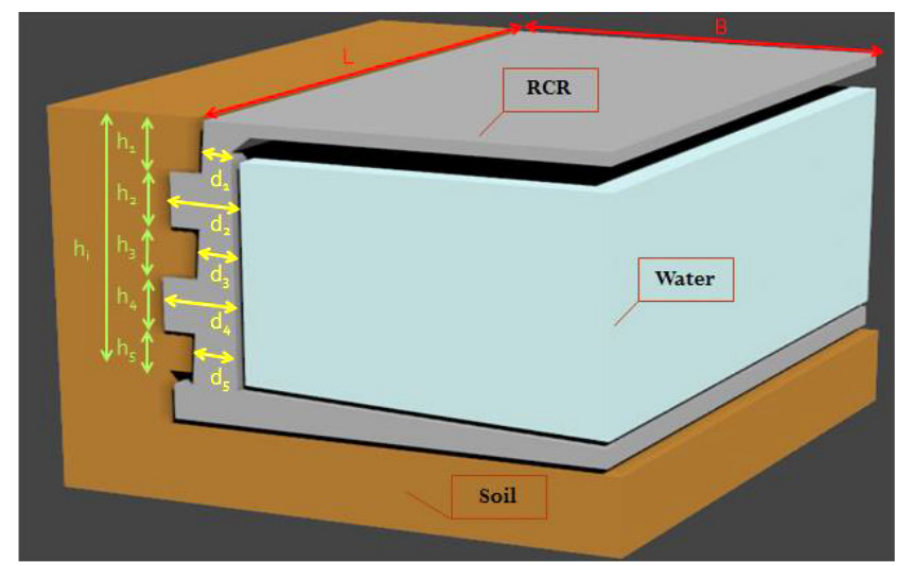

Fig. 4 Left: Optimization of RCR shear wall thickness, Right: RCR with prismatic stiffeners.

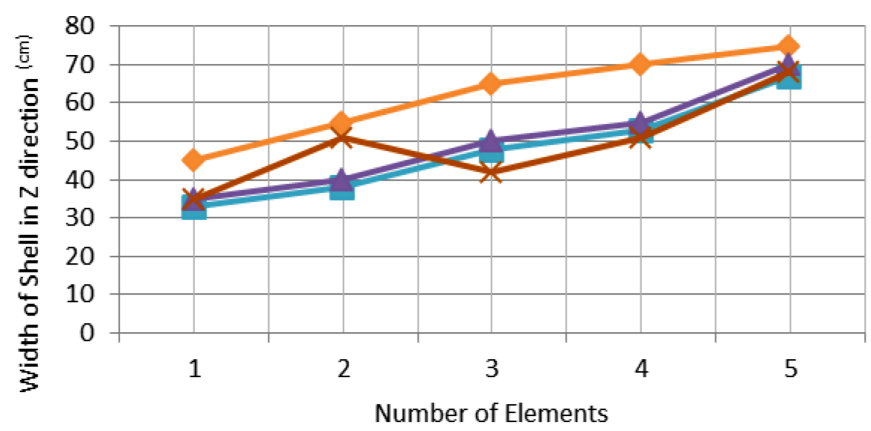

- Primary Structure
- Theoretical Optimization $\quad \longrightarrow$ Optimized by Stiffeners

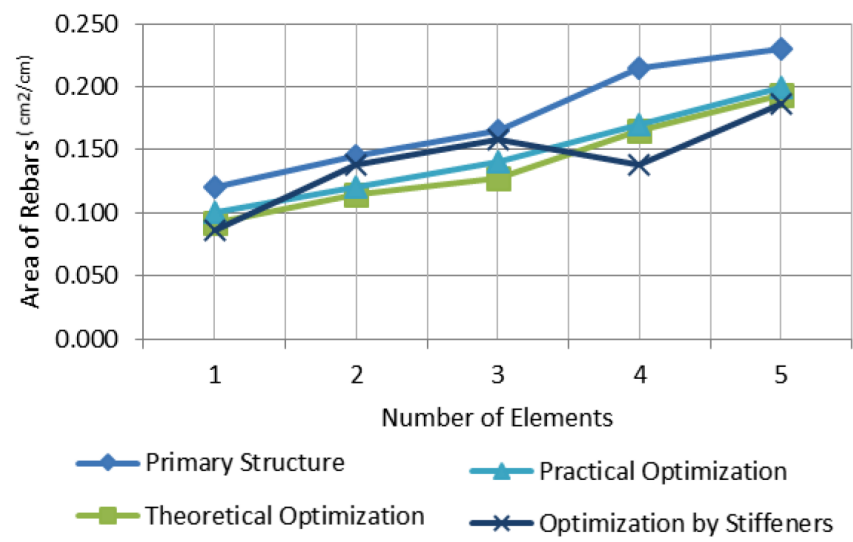

Fig. 6 Area of rebars in the RCR shell elements.

Fig. 5 Thickness of the RCR shell elements. 
Tab. 4 Comparison of the volume of the concrete, total weight of the rebars, and executive expenditures.

\begin{tabular}{|c|c|c|c|c|c|c|c|c|c|}
\hline \multirow{2}{*}{ No. } & \multirow{2}{*}{\multicolumn{2}{|c|}{ RCR Types }} & \multicolumn{2}{|c|}{ Concrete Mass } & \multicolumn{3}{|c|}{ Rebars } & \multicolumn{2}{|c|}{ Total Cost } \\
\hline & & & $\mathbf{m}^{3}$ & $\%$ & $\underset{(\mathrm{m})}{\text { Length }}$ & $\underset{(\mathrm{m})}{\text { Total }}$ & $\%$ & Billion IRR & $\%$ \\
\hline 1 & \multicolumn{2}{|c|}{ Traditional } & 639.84 & 0.00 & 107.65 & 204.54 & 0.00 & 13.00 & 0.00 \\
\hline 2 & \multirow{3}{*}{ 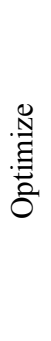 } & Theoretical & 493.30 & -23.00 & 85.80 & 163.02 & -20.00 & 11.14 & -14.00 \\
\hline 3 & & Practical & 516.00 & -19.00 & 89.88 & 170.98 & -16.00 & 11.48 & -12.00 \\
\hline 4 & & $\begin{array}{l}\text { Prismatic } \\
\text { Stiffeners }\end{array}$ & 509.81 & -20.00 & 86.78 & 164.88 & -19.00 & 11.31 & -13.00 \\
\hline
\end{tabular}

4. The performance is studied from different points of view and are as follows: the optimal weight of the structure, the rate of reducing the structural weight, the rate reducing the use of bars, and minimizing expenditures for small foundations on the items' list price of the department of planning and strategic supervisory regulation of technical affairs. This was performed based on three parameters, including reinforced concrete reservoirs with a conventional design, optimization of the reinforced concrete reservoir shell in two executive and theoretical states, and also optimization of the tank shell by a peripheral confirmatory sheath.

\section{CONCLUSION}

Rectangular concrete fluid reservoirs have different sizes based on the input discharge rate, while the overall structure's configuration is fixed and is influenced by the zone's soil mechanics, the site location, and the imposed static and dynamic loads. According to the study performed, concrete reservoirs, both in the section of the peripheral confirmatory thickness and by the peripheral confirmatory sheath, can be optimized based on the modeling performed and the relationship of the particle swarm in the bed of the PARIS algorithm. This study has resulted in a $20 \%$ reduction in the use of bars, a $23 \%$ reduction in the weight of the concrete used, and at least a $14 \%$ reduction in executive affairs based on a price list of the items in the structure by optimizing a $10,000 \mathrm{~m}^{3}$ reinforced concrete reservoir by a peripheral confirmatory sheath. The authors of this study believe that a parametric solution to all the assumptions discussed can optimize all the shell elements, ceiling and foundation by particle swarms for all concrete reservoirs having different sizes that will be perused in following articles. 


\section{REFERENCES}

Lloyd, A. R. - Doyle, W. S. (1978) Computer-aided design of circular liquid retaining structures in accordance with BS5337. Advances in Engineering Software, Vol. 3, No. 1, Jan. 1981, pp. $35-41$.

Mohaghegh, S. D. (2011) Reservoir simulation and modeling based on artificial intelligence and data mining (AI\&amp;DM). Journal of Natural Gas Science and Engineering, Vol. 3, No. 6, pp. 697-705.

Chen, J. Z. - Kianoush, M. R. (2009) Generalized SDOF system for seismic analysis of concrete rectangular liquid storage tanks. Engineering Structures, Vol. 31, No. 10, pp. 2426-2435.

Ziari, A. - Reza Kianoush, M. (2009) Investigation of flexural cracking and leakage in RC liquid containing structures. Engineering Structures, Vol. 31, No. 5, pp. 1056-1067.

Sanayei, M. - Santini Bell, E. - Rao, N. (2007) Model Updating of UCF Benchmark Model Using PARIS. In International Modal Analysis Conference, IMAC XXV, Orlando, USA, pp. 19-22.

Sanayei, M. - Wadia-Fascetti, S. - Arya, B. G. - Santini, E. G. (2001) Significance of Modeling Error in Structural Parameter Estimation. Special issue of the International Journal of Computer-Aided Civil and Infrastructure Engineering devoted to Health Monitoring of Structures, Vol. 16, pp. 12-27, pp. 12-27.

Yeh-Lianghsu (1994) A review of structural shape optimization, Computers in Industry. Vol. 25, No. 1, pp. 3-13.

Perez, R. E. - Behdinan, K. (2007) Particle swarm approach for structural design optimization, Computers and Structures. Vol. 85, Nos. 19 - 20, pp. 1579-1588.

Chau, K. W. - Lee, S. T. (1991) Computer-aided design package RCTank for the analysis and design of reinforced concrete tanks. Computers \& Structures, Vol. 41, No. 4, pp. 789-799.

Thevendran, V. - Thambiratnam, D. P. (1987) Optimal shapes of cylindrical concrete water tanks. Computers \& Structures, Vol. 26, No. 5, 1987, pp. 805-810.
Hinton, E. - Rao, N. V. R. (1993) Structural shape optimization of shells and folded plates using two-noded finite strips. Computers \& Structures, Vol. 46, No. 6, 17, pp. 1055-1071.

White, D. W. - Abel, J. F. (1989) Testing of shell finite element accuracy and robustness, Finite Elements in Analysis and Design. Vol. 6, No.2, pp. 129-151.

MacNeal, R. H. - Harder, R. L. (1985) A proposed standard set of problems to test finite element accuracy. Finite Elements in Analysis and Design, Vol. 1, No. 1, April 1985, pp. 3-20.

Peng, X. (1998) Application of generalized function theory on the complete solutions of plates and shells. Applied Mathematical Modelling", Vol. 12, No. 3, pp. 321-327.

Sundar, S. - Singh, A. (2012) A swarm intelligence approach to the early/tardy scheduling problem. Swarm and Evolutionary Computation”, Vol. 4, pp. 25-32.

Rao, N. V. R. - Hinton, E. (1994) Analysis and optimization of prismatic plate and shell structures with curved plan form II Shape optimization. Computers \& Structures, Vol. 52, No. 2, pp. 341-351.

Lee, K. S. - Geem, Z. W. (2004) A new structural optimization method based on the harmony search algorithm. Computers \& Structures, Vol. 82, Nos. 9-10, April 2004, pp. 781-798.

Mousa, A. A. - El-Shorbagy, M. A. - Abd-El-Wahed, W. F. (2012) Local search based hybrid particle swarm optimization algorithm for multiobjective optimization. Swarm and Evolutionary Computation, Vol. 3, pp. 1-14.

Seed, H. B. - Whitman, R. V. (1970) Design of Earth Retaining Structures for Dynamic Loads. ASCE Specialty Conference, Lateral Stress in the Ground and Design of Earth Retaining Structures, pp. 103-147. 